\title{
Knowledge of risk factors for hypertension in a rural Indian population
}

\author{
Doreen Busingye, ${ }^{01}$ Simin Arabshahi, ${ }_{1}^{1}$ Roger G Evans, ${ }^{2}$ Michaela A Riddell, ${ }^{1}$ \\ Velandai K Srikanth, ${ }_{1}^{1}$ Kamakshi Kartik, ${ }^{3}$ Kartik Kalyanram, ${ }^{3}$ Xuan Zhu, ${ }_{1}^{4}$ Oduru Suresh, ${ }^{3}$ \\ George Howard, ${ }^{5}$ Amanda G Thrift ${ }^{1}$
}

${ }^{1}$ Medicine, Monash University, Clayton, Victoria, Australia ²Physiology, Monash University, Clayton, Victoria, Australia ${ }^{3}$ Rishi Valley Rural Health Centre, Madanapalle, Andhra Pradesh, India

${ }^{4}$ School of Earth, Atmosphere and Environment, Monash University, Clayton, Victoria, Australia

${ }^{5}$ Biostatistics, University of Alabama at Birmingham, Birmingham, Alabama, USA

\section{Correspondence to}

Dr Doreen Busingye, Medicine, Monash University, Clayton, VIC 3168, Australia; doreen. busingye@monash.edu

Received 16 October 2018 Revised 22 January 2019 Accepted 4 February 2019

\section{Check for updates}

(C) Author(s) (or their employer(s)) 2019. No commercial re-use. See rights and permissions. Published by BMJ.

\footnotetext{
To cite: Busingye $D$,

Arabshahi S, Evans RG,

et al. Heart Asia

2019;11:e011136.

doi:10.1136/

heartasia-2018-011136
}

\section{ABSTRACT}

Objective To study knowledge of risk factors and

consequences of hypertension in a rural population in

South India.

Methods This is a community-based study conducted among adults of a rural population in the Rishi Valley, India. Residents of randomised rural villages were invited to participate in a study of hypertension. We obtained measures of blood pressure, height, weight, waist and hip circumferences and questionnaire-based information on knowledge about hypertension, sociodemographic characteristics and health behaviours. Multivariable logistic regression analyses were conducted to determine the factors associated with knowledge of risk factors for hypertension (knowledge of $\geq 2$ risk factors).

Results The study comprised 641 adults; 132 aware and 218 unaware of their hypertension, and 291 with normal blood pressure. Only 31\% of participants knew that hypertension adversely affects an individual's health and $7 \%$ knew the benefits of treating hypertension. Almost a third (30\%) of those aware of their hypertensive status, and $48 \%$ overall, did not know any of the risk factors for hypertension. Being aware of one's hypertensive status (OR 2.51, 95\% Cl 1.44 to 4.39), being treated for hypertension, male sex, younger age, having some schooling, abdominal obesity and physical inactivity were associated with better knowledge of risk factors for hypertension.

Conclusion Knowledge of risk factors and consequences of hypertension in this disadvantaged population was poor. There was better knowledge of risk factors in some, but not all, people who were aware of having hypertension. Screening and targeted educational programmes are warranted in this population to improve health behaviours and reduce the consequences of hypertension.

\section{INTRODUCTION}

Hypertension is the leading modifiable risk factor for mortality and burden of disease in high-income and low-to middle-income countries (LMICs). ${ }^{1}$ In some LMICs the prevalence of hypertension is still on the rise and rural populations are not immune to this rise. ${ }^{2}$

Despite major global attempts to reduce hypertension, treatment and control of hypertension remain inadequate. ${ }^{3}$ Attaining better control of hypertension should be possible with the use of effective and affordable blood pressure (BP) lowering agents and by reducing factors that increase the risk of hypertension, such as obesity/overweight, physical inactivity, poor diet and alcohol intake. ${ }^{4}$

\section{Key messages}

What is already known about this subject?

- Hypertension is an important risk factor for cardiovascular disease and is the most important modifiable risk factor for mortality and burden of disease globally.

- The prevalence of hypertension in rural Indian populations is increasing, but there is limited information about knowledge of risk factors for hypertension in this population.

What does this study add?

- Knowledge of risk factors for hypertension is poor, irrespective of whether participants are aware or unaware of their hypertensive status or have normal blood pressure.

- Awareness of one's hypertensive status, treatment for hypertension, male sex, young age, some schooling, abdominal obesity and physical inactivity were identified as factors associated with better knowledge of risk factors for hypertension.

How might this impact on clinical practice?

- Findings of this study highlight poor knowledge of modifiable risk factors and consequences of hypertension in a disadvantaged rural Indian population. This underscores the need for screening programmes to increase awareness of hypertension, and broadly targeted educational programmes aimed at improving knowledge throughout the community. Awareness of hypertension and adequate health education may improve knowledge of hypertension, and this may be translated into better blood pressure control.

Importantly, one of the factors associated with control of BP is better knowledge about hypertension and the risk factors for the development of hypertension. ${ }^{56}$ More knowledge is associated with better adherence to antihypertensive medications ${ }^{78}$ and adoption of a more healthy lifestyle, ${ }^{9}{ }^{10}$ both being potential mechanisms for improving control.

There is a considerable body of information describing knowledge about hypertension in high-income countries. ${ }^{11-13}$ However, in LMICs, where the largest burden of hypertension occurs, ${ }^{14}$ there are few data about knowledge of hypertension, particularly in disadvantaged rural populations. It is also unclear whether there is better knowledge about hypertension among those aware 
of their hypertension than those unaware, as has been reported in urban regions. ${ }^{15}$

Effective future community-based education programmes rely on an accurate assessment of the baseline knowledge of a population. Therefore, using data from a carefully conducted case-control study in South India, enriched with individuals with hypertension, we aimed to determine knowledge of (1) risk factors for hypertension and (2) consequences of hypertension for long-term health. Findings from our study could provide the impetus for greater efforts in community screening and health education.

\section{METHODS}

\section{Study design}

This was a community-based observational study conducted from August 2012 to August 2014.

\section{Study population and recruitment of participants}

The setting for this project was a disadvantaged and largely illiterate community, living in rural villages of the Rishi Valley region, Southern Andhra Pradesh. The population of the Rishi Valley is about 38000 , and the language commonly spoken is Telugu.

The sampling frame consisted of two sources, the main being a case-control study of risk factors for hypertension. Randomisation was undertaken at the village (hamlet) level. The villages participating in the case-control study were chosen using stratified random sampling, with three strata (small, medium, large) based on size of the population, and a similar number of villages in each stratum. Based on the population census, villages were considered to be small if the population was $\leq 52,>52$ to $\leq 145$ for medium and $>145$ for large-sized villages. There were 19 small, 22 medium and 22 large villages included in the study. In order to identify residents with (cases) and those without (controls) hypertension, it was necessary to first screen the population in the randomised villages. All individuals aged $\geq 18$ years and residing in the randomised villages were eligible and were invited to participate in the screening. Following screening, individuals with hypertension (systolic $\mathrm{BP} \geq 140 \mathrm{~mm} \mathrm{Hg}$ and/ or diastolic $\mathrm{BP} \geq 90 \mathrm{~mm} \mathrm{Hg}$ ) were approached and invited to participate. Participants with hypertension were approached in the order in which they were first identified. After each case had been recruited and assessed, a potential matched control (by sex and age) was randomly selected from the pool of potential controls.

All participants recruited into the case-control study were included in the present study; originally this comprised 300 people with hypertension and 300 people without hypertension matched by age and sex to cases. However, there were nine controls with inconsistent data on awareness and treatment of hypertension between screening and clinic assessment, and following careful review, all were recategorised as hypertensive. An additional smaller sample of 41 people with hypertension who were excluded from the case-control study was also included. These comprised 15 people with hypertension for whom no age and sex-matched control could be identified, and 26 who were taking antihypertensive medication at screening, and had controlled hypertension (systolic BP $<140 \mathrm{~mm} \mathrm{Hg}$ and diastolic BP $<90 \mathrm{~mm} \mathrm{Hg}$ ).

At the end of the screening process all individuals who were identified as having a systolic BP $\geq 140 \mathrm{~mm} \mathrm{Hg}$ or a diastolic BP $\geq 90 \mathrm{~mm} \mathrm{Hg}$ were informed that they may have hypertension and advised to consult their doctor. Approximately $12 \%$ of the population screened had $\mathrm{BP} \geq 140 / 90 \mathrm{~mm} \mathrm{Hg}$.

\section{Data collection and measurements}

Questionnaire-based, physical and clinical measurements for most participants were performed. Trained research personnel administered questionnaires and measured BP and anthropometric parameters. The instruments and measurements used for this study were in accordance with the recommendations from the WHO STEPwise approach to (non-communicable disease) risk factor surveillance (STEPS). ${ }^{16}$ The questionnaire was translated into Telugu, the native language, and then back translated into English to check for any errors that might lead to misinterpretation of either the questions or the answers. This questionnaire was used to collect information on sociodemographics including age, sex, traditional social group, religion, marital status, educational attainment and type of work undertaken; lifestyle-related behaviours, including tobacco use, alcohol consumption and physical activity; and knowledge about hypertension and its risk factors, routine habits for health check-ups and access to healthcare.

$\mathrm{BP}$ was measured using a digital automatic BP monitor (OMRON HEM-907) in accordance with the WHO STEPS surveillance protocol. ${ }^{16}$ Participants were seated for at least 15 min before the first BP measurement was taken. BP was measured from the right arm, where possible, with the arm supported at the level of the heart. At least three BP measurements were taken, with a rest period of $3 \mathrm{~min}$ between each measurement. BP measurements were taken until the last two measurements differed by $<10 \mathrm{~mm} \mathrm{Hg}$ for systolic BP and $<6 \mathrm{~mm} \mathrm{Hg}$ for diastolic BP, up to a maximum of five measurements. The mean of the last two measurements was used to define hypertensive status. This procedure was used both during the screening exercise and during the day of clinical assessment.

Height was measured to the nearest $0.1 \mathrm{~cm}$ using a standard portable stadiometer (SECA 213). Weight was measured, in light clothes, to the nearest $0.1 \mathrm{~kg}$ using a standard calibrated portable electronic scale (Salter 9000SV3R). Waist and hip circumferences were measured using a constant-tension Gulick tape in privacy, behind a screen.

\section{Assessment of knowledge of risk factors and consequences of hypertension}

Participants responded 'yes', 'no' or 'I do not know' to indicate whether they thought the following factors help reduce BP: (1) reducing alcohol consumption; (2) loss of weight for those who are overweight or obese; (3) increasing intake of fresh fruits and vegetables; (4) increasing physical activity; and (5) reducing salt intake. Knowledge scores were calculated for each participant based on the number of options selected. Participants received 1 point for each 'yes' response option about knowledge of the five modifiable risk factors. Knowledge scores ranged from 0 to 5 .

Additional questions were asked to examine knowledge of the consequences of hypertension, for example, effects of hypertension on one's health, and to ascertain whether participants were aware that treating hypertension reduces the likelihood of other diseases.

\section{Definitions}

The outcome measure was knowledge of more than one (median knowledge score) of the listed modifiable risk factors for hypertension. Hypertension was considered to be present when, at either screening assessment or on the day of clinical assessment, the mean of the last two measurements was at least $140 \mathrm{~mm}$ 
$\mathrm{Hg}$ for systolic BP and/or at least $90 \mathrm{~mm} \mathrm{Hg}$ for diastolic BP, or self-reported use of antihypertensive medications. Participants without hypertension (normotensive) are those who had a mean BP less than 140/90 mm Hg at both screening and clinic assessment, and did not report use of antihypertensive medications at screening or the clinic assessment.

Awareness of hypertension was defined as self-reported prior diagnosis of hypertension by a health professional. ${ }^{17}$ Unawareness of hypertension was defined as having at least $140 \mathrm{~mm} \mathrm{Hg}$ for systolic BP and/or at least $90 \mathrm{~mm} \mathrm{Hg}$ for diastolic BP but with no self-reported prior diagnosis of hypertension.

Obesity was defined as body mass index (BMI) at least 25 $\mathrm{kg} / \mathrm{m}^{2}$, overweight as BMI at least $23 \mathrm{~kg} / \mathrm{m}^{2}$ and less than 25 $\mathrm{kg} / \mathrm{m}^{2}$, and underweight as BMI less than $18 \mathrm{~kg} / \mathrm{m}^{2}$, based on the standard cut-off values for Indians. ${ }^{18}$ Physical inactivity was defined as work that involved mostly sitting or standing. Eversmokers comprised individuals who reported that they smoked any tobacco product including cigarettes and bidis (small handrolled cigarettes) at least daily and those who smoked at least daily in the past. Ever-smokeless tobacco use was defined when tobacco products such as snuff, chewing tobacco and betel were used, at least daily either currently or in the past. Current alcohol consumption was defined as drinking alcohol at least once in the 12 months prior to the date of the survey.

Participants were categorised as 'traditionally advantaged' and 'traditionally disadvantaged' according to their traditional social group. These traditional groups have been shown to be strong determinants of socioeconomic position and poverty in the Indian context. ${ }^{19}$

\section{Statistical analysis}

Individuals were categorised into three groups by hypertension status and awareness: those with hypertension who were aware of diagnosis, those with hypertension who were unaware and those with normal BP. The group of individuals with hypertension who were unaware were considered as a reference category. Therefore, for descriptive analyses of general characteristics and knowledge of risk factors and consequences of hypertension, two formal comparisons were performed: those with hypertension who were aware versus those with hypertension who were unaware ( $p$ values for these comparisons were coded as ' $p_{\text {awareness }}$ '), and those with hypertension who were unaware versus those with normal BP ( $p$ values for these comparisons were coded as ' $p_{\text {normotensive }}$ '). Thus, this analysis allowed us to separately assess the impact of awareness of hypertension on knowledge about hypertension in individuals with the condition, and the impact of hypertension on knowledge in the absence of awareness. The $\chi^{2}$ test was used to compare knowledge of hypertension between each of the two groups. To control type I error, these $\mathrm{p}$ values were adjusted, to account for the fact that two comparisons were made, using the Dunn-Sidak correction. ${ }^{20}$

To identify factors associated with knowledge of risk factors for hypertension, univariable and multivariable logistic regression analyses were performed using knowledge of more than one risk factor (median knowledge score) as a dependent variable. Three multivariable models were constructed for men and women combined and separately for each sex. All relevant variables such as age, sex, traditional social group, educational attainment, hypertension status and awareness (with hypertension and aware, with hypertension and unaware, and with normal BP), and so on were introduced into multivariable regression analyses in a backward stepwise fashion. Apart from age, sex, and hypertension status and awareness, which were forced in the model, only variables with a $\mathrm{p}$ value $\leq 0.1$ in backward stepwise selection were retained in the final models. We further undertook similar analyses on the association between knowledge of risk factors and treatment with antihypertensive medications. Two-sided $\mathrm{p}$ values $\leq 0.05$ were considered statistically significant in all analyses. Data were analysed using STATA (V.12; StataCorp, College Station, TX, USA).

\section{RESULTS}

Our study comprised 641 adults: 132 with hypertension who were aware and 218 who were unaware of their hypertensive condition and 291 people with normal BP. Seventy-eight per cent of the adults in the randomised villages participated in the screening exercise. Of the total number of individuals who were identified as potential cases and controls from the sample screened for hypertension, $84 \%$ of cases and $73 \%$ of controls were successfully recruited. The median age for all participants was 60 years (Q1, Q3; 50, 70), and $55 \%$ were men (table 1 ).

\section{Knowledge of risk factors and consequences of hypertension}

Only 31\% of participants knew that hypertension adversely affects an individual's health, $7 \%$ knew the benefits of treating hypertension and $12 \%$ or fewer knew that BP could be lowered by reducing alcohol consumption, losing weight, increasing intake of fresh fruits and vegetables or increasing physical activity. Interestingly, more people knew that salt was a risk factor for hypertension (50\%) than any of the other risk factors (range 9\%-12\%). Those aware of their hypertension and people with normal BP were more likely to know that hypertension adversely affects an individual's health, or that treating hypertension prevents other diseases, than people who were unaware that they had hypertension (table 2).

Compared with those unaware of their hypertension, individuals who were aware of the condition were approximately twice as likely to report that increasing intake of fresh fruits and vegetables and increasing physical activity help in reducing BP (table 2). There were no detectable differences in knowledge of each of the risk factors between individuals who were unaware of their hypertensive status and people whose BP was within the normal range.

People aware of their hypertension more often knew at least two risk factors for hypertension (33\%) than those unaware of their hypertension $(19 \%)$ or those with normal BP (14\%; table 2). In addition, fewer women knew of at least two risk factors (13\%) than men (26\%; figure 1$)$.

\section{Factors associated with knowledge of risk factors for hypertension}

Overall, individuals who were aware that they had hypertension were twice as likely to have better knowledge of risk factors than those who were not aware of their condition (OR 2.51, 95\% CI 1.44 to 4.39 ; table 3 ). Other factors that were independently associated with better knowledge of risk factors for hypertension were younger age, male sex, having some schooling, waist circumference above normal cut-off levels and being physically inactive (table 3). Results were similar in analyses restricted to men, except that having a waist circumference greater than $90 \mathrm{~cm}$ was not independently associated with better knowledge of risk factors (table 3). In analyses restricted to women, the only factors associated with better knowledge of risk factors were being aware of hypertension (OR 2.66, 95\% CI 1.09 to 6.46) and having a waist circumference greater than $80 \mathrm{~cm}$ (table 3 ).

We found that individuals with hypertension who reported taking antihypertensive medication were three times as likely to have better knowledge of risk factors than those who were not 
Table 1 Characteristics of individuals with hypertension who are aware and unaware of their hypertensive status, as well as those with normal blood pressure

\begin{tabular}{|c|c|c|c|c|c|}
\hline \multirow[b]{2}{*}{ Characteristic } & $\begin{array}{l}\text { With hypertension and } \\
\text { aware } \\
(\mathrm{n}=132)\end{array}$ & $\begin{array}{l}\text { With hypertension and } \\
\text { unaware } \\
(n=218)\end{array}$ & \multirow[b]{2}{*}{$\mathbf{p}_{\text {awareness }}$} & \multirow{2}{*}{$\begin{array}{l}\text { With normal BP } \\
(\mathrm{n}=291)\end{array}$} & \multirow[b]{2}{*}{$\mathbf{p}_{\text {normotensive }}$} \\
\hline & \multicolumn{2}{|l|}{$\mathrm{n}(\%)^{*}$} & & & \\
\hline Male & $65(49)$ & $123(56)$ & 0.43 & $165(57)$ & 1.00 \\
\hline \multicolumn{6}{|l|}{ Social group } \\
\hline Traditionally advantaged & $18(14)$ & $30(14)$ & 1.00 & $11(4)$ & $<0.001$ \\
\hline \multicolumn{6}{|l|}{ Religion } \\
\hline Hindu & $108(82)$ & $196(90)$ & 0.26 & $265(91)$ & 0.26 \\
\hline Muslim & $19(14)$ & $16(7)$ & & $25(9)$ & \\
\hline Christian & $5(4)$ & $6(3)$ & & $1(0)$ & \\
\hline \multicolumn{6}{|l|}{ Educational attainment $\dagger$} \\
\hline Non-farmersł & $77(58)$ & $95(44)$ & 0.02 & $89(31)$ & 0.01 \\
\hline Farming and livestock & $55(42)$ & $123(56)$ & & $202(69)$ & \\
\hline \multicolumn{6}{|l|}{ Marital status } \\
\hline One wife/husband & $83(63)$ & $143(66)$ & 0.89 & $208(71)$ & 0.24 \\
\hline More than one wife/husband & $9(7)$ & $18(8)$ & & $12(4)$ & \\
\hline Not married (divorced, widowed, never married) & $40(30)$ & $57(26)$ & & $71(25)$ & \\
\hline \multicolumn{6}{|l|}{ BMI category $\left(\mathrm{kg} / \mathrm{m}^{2}\right) \S$} \\
\hline Underweight $(<18)$ & $31(24)$ & $54(25)$ & 0.30 & $93(32)$ & 0.26 \\
\hline Normal ( $\geq 18$ and $<23$ ) & $55(43)$ & $109(51)$ & & $135(47)$ & \\
\hline Overweight $(\geq 23$ and $<25$ )/obese $(\geq 25)$ & $43(33)$ & $52(24)$ & & $59(21)$ & \\
\hline WC, above normal (men, $>90 \mathrm{~cm}$; women, $>80 \mathrm{~cm}$ ) & $32(24)$ & $48(22)$ & 0.86 & $36(12)$ & 0.007 \\
\hline Regular health check-up ( $\geq 1$ in the past year) & $103(78)$ & $116(53)$ & $<0.001$ & $120(41)$ & 0.02 \\
\hline Last time BP was measured ( $\leq 1$ year ago) & 100 (76) & $76(35)$ & $<0.001$ & $110(38)$ & 0.75 \\
\hline Taking antihypertensive medication & $75(57)$ & $0(0)$ & $<0.001$ & $0(0)$ & - \\
\hline No health insurance & $24(18)$ & $50(23)$ & 0.50 & $39(13)$ & 0.01 \\
\hline \multicolumn{6}{|l|}{ Distance to health services $(\mathrm{km})$} \\
\hline$\leq 5$ & $71(54)$ & $83(38)$ & 0.01 & $124(43)$ & 0.51 \\
\hline$>5$ & $61(46)$ & $135(62)$ & & $167(57)$ & \\
\hline
\end{tabular}

P values are the outcomes of Pearson's $\chi^{2}$ test for categorical data and Kolmogorov-Smirnov test for continuous data. $p_{\text {awareness }} p$ value for difference between those with hypertension and aware $(n=132)$ versus those with hypertension and unaware $(n=218)$. $p_{\text {normotensive }} p$ value for difference between those with hypertension and unaware $(n=218)$ versus with normal blood pressure $(n=291)$. $P$ values are adjusted by the Dunn-Sidak correction to account for the fact that two comparisons were made.

${ }^{*}$ Percentage unless otherwise specified.

tNine observations missing.

łIndividuals in this category of work were either employed, homemaker, student or retired.

$\S$ Ten observations missing.

ๆFour observations missing

** Two observations missing.

BMI, body mass index; BP, blood pressure; DBP, diastolic blood pressure; Q1, quartile 1; Q3, quartile 3; SBP, systolic blood pressure; WC, waist circumference.

taking medication (OR 3.36, 95\% CI 1.78 to 6.31 ; table 4). Similar findings were observed for men and women separately (table 4).

\section{DISCUSSION}

Our most important finding is that there is rudimentary knowledge of the adverse effects of hypertension, while most of the studied population has poor knowledge of the risk factors and importance of treatment. Even in people who were aware of their hypertension, one-third (30\%) were unaware of any of the modifiable risk factors for hypertension and most (88\%) did not know that treating hypertension prevents other diseases. Knowledge was even poorer in those who were unaware that they had hypertension, and in women. Having some schooling, a waist circumference indicating abdominal obesity and physical 
Table 2 Knowledge of risk factors and consequences of hypertension among individuals with hypertension who were aware and unaware of their hypertensive status, as well as those with normal blood pressure

\begin{tabular}{|c|c|c|c|c|c|}
\hline \multirow[b]{2}{*}{ Characteristic } & $\begin{array}{l}\text { With hypertension } \\
\text { and aware } \\
(\mathrm{n}=132)\end{array}$ & $\begin{array}{l}\text { With hypertension } \\
\text { and unaware } \\
(\mathrm{n}=218)\end{array}$ & \multirow[b]{2}{*}{$\mathbf{p}_{\text {awareness }}$} & \multirow{2}{*}{$\begin{array}{l}\text { With normal BP } \\
(\mathrm{n}=291) \\
\mathrm{n}(\%)^{*}\end{array}$} & \multirow[b]{2}{*}{$p_{\text {normotensive }}$} \\
\hline & \multicolumn{2}{|l|}{$\mathrm{n}(\%)^{*}$} & & & \\
\hline \multicolumn{6}{|c|}{ How does hypertension affect one's health? } \\
\hline It adversely affects health. & $63(48)$ & $43(20)$ & $<0.001$ & $90(31)$ & 0.006 \\
\hline I have no idea/l don't know. & $69(52)$ & $175(80)$ & & $201(69)$ & \\
\hline \multicolumn{6}{|c|}{$\begin{array}{l}\text { Treating hypertension reduces likelihood of other } \\
\text { diseases. }\end{array}$} \\
\hline Yes & $16(12)$ & $8(4)$ & 0.006 & $20(7)$ & 0.19 \\
\hline No/Don't know & $116(88)$ & $210(96)$ & & $271(93)$ & \\
\hline \multicolumn{6}{|c|}{ Treating hypertension reduces likelihood of: $\dagger$} \\
\hline Heart disease & $4(25)$ & $1(12)$ & 0.85 & $3(15)$ & 0.79 \\
\hline Stroke & $2(13)$ & $0(0)$ & & $2(10)$ & \\
\hline Heart disease and stroke & $7(44)$ & $5(63)$ & & $6(30)$ & \\
\hline Heart disease and cancer & $0(0)$ & $0(0)$ & & $2(10)$ & \\
\hline Don't know & $3(18)$ & $2(25)$ & & $7(35)$ & \\
\hline \multicolumn{6}{|c|}{ Do the following help reduce blood pressure? } \\
\hline \multicolumn{6}{|c|}{ Reducing alcohol consumption } \\
\hline Yes & $20(15)$ & $25(11)$ & 0.54 & $30(10)$ & 0.90 \\
\hline No/Don't know & $112(85)$ & $193(89)$ & & $261(90)$ & \\
\hline \multicolumn{6}{|c|}{ Weight loss in those who are overweight } \\
\hline Yes & $21(16)$ & $21(10)$ & 0.15 & $16(6)$ & 0.15 \\
\hline No/Don't know & $111(84)$ & $197(90)$ & & $275(94)$ & \\
\hline \multicolumn{6}{|c|}{ Increasing intake of fresh fruits and vegetables } \\
\hline Yes & $31(23)$ & $21(10)$ & 0.001 & $23(8)$ & 0.74 \\
\hline No/Don't know & $101(77)$ & $197(90)$ & & $268(92)$ & \\
\hline \multicolumn{6}{|l|}{ Increasing physical activity } \\
\hline Yes & $20(15)$ & $18(8)$ & 0.07 & $25(9)$ & 0.99 \\
\hline No/Don't know & $112(85)$ & $200(92)$ & & $266(91)$ & \\
\hline \multicolumn{6}{|l|}{ Reducing salt intake $\ddagger$} \\
\hline Yes & $91(69)$ & $101(47)$ & $<0.001$ & $130(45)$ & 0.92 \\
\hline No/Don't know & $41(31)$ & $116(53)$ & & $161(55)$ & \\
\hline \multicolumn{6}{|c|}{ Number of risk factors correctly identified } \\
\hline 0 & $40(30)$ & $111(51)$ & 0.02 & $154(53)$ & 0.99 \\
\hline 1 & $48(36)$ & $65(30)$ & & $95(33)$ & \\
\hline 2 & $18(14)$ & $22(10)$ & & $17(6)$ & \\
\hline 3 & $11(8)$ & $8(4)$ & & $12(4)$ & \\
\hline 4 & $9(7)$ & $7(3)$ & & $6(2)$ & \\
\hline 5 & $6(5)$ & $5(2)$ & & $7(2)$ & \\
\hline Median score (Q1, Q3) & $1(0,2)$ & $0(0,1)$ & 0.008 & $0(0,1)$ & 1.00 \\
\hline
\end{tabular}

$P$ values are the outcomes of Pearson's $\chi^{2}$ test for categorical data and Kolmogorov-Smirnov test for continuous data. $p$ aware $(n=132)$ versus those with hypertension and unaware $(n=218) . p_{\text {normotensive }} p$ value for difference between those with hypertension and unaware $(n=218)$ versus with normal blood pressure $(n=291)$. $P$ values are adjusted by the Dunn-Sidak correction to account for the fact that two comparisons were made.

${ }^{*}$ Percentage unless otherwise specified.

tIncludes only those who answered 'Yes' to whether treating hypertension reduces likelihood of other diseases.

$\ddagger$ ne missing observation for those unaware of their hypertensive status.

$\mathrm{BP}$, blood pressure; Q1, quartile 1; Q3, quartile.

inactivity were factors associated with better knowledge about hypertension.

The widespread lack of knowledge of the importance of treatment and knowledge of risk factors for hypertension in this disadvantaged population is alarming and merits broadly targeted public health interventions to improve knowledge in this community and other similar communities in India and other LMICs. Such poor knowledge may be attributable to an overburdened health system that is focused mainly on communicable diseases, lack of formal school education and inaccessibility to routine health education programmes. ${ }^{21} 22$ Because knowledge of risk factors for cardiovascular disease (CVD) has been associated with making healthy behavioural changes, ${ }^{23}$ improving knowledge about hypertension in rural communities may lead to adoption of healthy behavioural changes and a subsequent reduction in the burden of hypertension and CVD. ${ }^{9} 10$ Therefore, our findings highlight the critical need for interventional programmes aimed at educating communities about the risk factors and consequences of hypertension.

Interestingly, while knowledge of risk factors is equally poor in people with normal BP and those unaware of their hypertension, those with normal BP have slightly better knowledge 


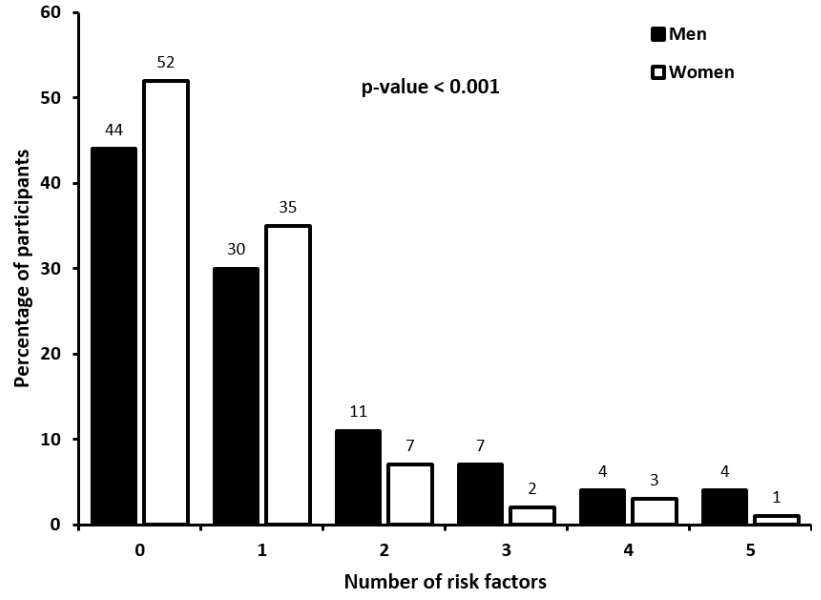

Figure 1 Knowledge of risk factors for hypertension in men and women. The $p$ value is the outcome of Pearson's $\chi^{2}$ test, to detect sex differences in knowledge of at least two risk factors.

of consequences. The underlying causes of this difference in knowledge remain to be established. One possibility is that, by dividing the group of people with hypertension into subgroups of those aware and unaware of their status, we revealed underlying differences between the groups of individuals in terms of their engagement with their own health. That is, the group of individuals with hypertension who were unaware of their hypertensive status might include a larger proportion of those with major barriers to accessing healthcare than the general population. This is particularly relevant as all those identified as having high $\mathrm{BP}$ at the screening phase were informed about their status and were advised to follow-up with a doctor to confirm the diagnosis.

Notably, people who are aware of their hypertension had better knowledge of the consequences of hypertension than those who are unaware of their condition or those with normal BP. Our findings indicate that awareness of one's hypertensive status and taking antihypertensive medication are independently associated with better knowledge of risk factors for hypertension in this population, and could be a mechanism for improving knowledge about hypertension. This could be achieved by introducing screening programmes for hypertension in this community to improve diagnosis and, potentially, knowledge.

There is evidence that individuals in disadvantaged rural populations are less likely to have ever had their BP, blood glucose or cholesterol screened than people who are more advantaged as measured by educational attainment or a greater income. ${ }^{23}$ Therefore, screening in disadvantaged communities should be considered as a major focus of prevention. Recommendations to measure BP as a routine procedure for clinical visits and provision of preventive primary healthcare services that encourage people to have their BP monitored more regularly are likely to improve awareness of hypertension and knowledge of risk factors in this population.

While increasing diagnosis of hypertension has the potential to improve knowledge of risk factors in those who are affected, more widespread public education about hypertension may empower communities to reduce the likelihood of individuals developing hypertension. Educational programmes have been shown to be feasible and effective in rural communities, ${ }^{9}{ }^{10}$ with effective strategies including educational programmes delivered by local healthcare staff, print media and health education sessions, as used in rural China. ${ }^{10}$

Future community-based educational programmes could use cost-effective strategies such as mobile health (mHealth) or electronic health interventions, which can be tailored to the targeted population, to improve cardiovascular-related knowledge, lifestyle behaviours and management of disease. ${ }^{24}$ This may be a particularly effective approach in rural India since the majority of rural Indians own a mobile phone. This approach to dissemination of health information has been shown to be acceptable in rural Indian populations. ${ }^{25}$ Studies of mHealth interventions, such as individual-directed short message service to improve knowledge and management of

Table 3 Factors associated with knowledge of at least two risk factors for hypertension

\begin{tabular}{|c|c|c|c|c|c|c|}
\hline \multirow[b]{2}{*}{ Factors } & \multicolumn{2}{|l|}{ All } & \multicolumn{2}{|l|}{ Men } & \multicolumn{2}{|l|}{ Women } \\
\hline & $\begin{array}{l}\text { Univariable } \\
\text { analysis } \\
\text { OR (95\% CI) }\end{array}$ & $\begin{array}{l}\text { Multivariable } \\
\text { analysis* } \\
\text { OR }(95 \% \mathrm{Cl})\end{array}$ & $\begin{array}{l}\text { Univariable } \\
\text { analysis } \\
\text { OR (95\% CI) }\end{array}$ & $\begin{array}{l}\text { Multivariable } \\
\text { analysis* } \\
\text { OR }(95 \% \mathrm{Cl})\end{array}$ & $\begin{array}{l}\text { Univariable } \\
\text { analysis } \\
\text { OR }(95 \% \mathrm{Cl})\end{array}$ & $\begin{array}{l}\text { Multivariable } \\
\text { analysis* } \\
\text { OR }(95 \% \mathrm{Cl})\end{array}$ \\
\hline Age, year (continuous) & 0.97 (0.95 to 0.98$)$ & 0.97 (0.95 to 0.99$)$ & 0.97 (0.95 to 0.99$)$ & $0.97(0.95$ to 0.99$)$ & 0.97 (0.94 to 1.00$)$ & 0.97 (0.94 to 1.00$)$ \\
\hline Male & 2.59 (1.69 to 3.96$)$ & 2.51 (1.37 to 4.59 ) & - & - & - & - \\
\hline \multicolumn{7}{|l|}{ Educational attainment† } \\
\hline No formal schooling & 1.00 & 1.00 & 1.00 & 1.00 & 1.00 & \\
\hline Some schooling & 3.59 (2.36 to 5.45$)$ & 1.96 (1.16 to 3.32$)$ & 3.11 (1.69 to 5.72$)$ & 2.21 (1.16 to 4.21$)$ & 2.79 (1.26 to 6.20$)$ & - \\
\hline WC above normal $\ddagger$ & 2.87 (1.84 to 4.47$)$ & 1.95 (1.17 to 3.25 ) & $2.90(1.62$ to 5.19$)$ & - & 3.71 (1.76 to 7.84$)$ & $2.62(1.15$ to 5.94$)$ \\
\hline Physical inactivity & 1.74 (1.18 to 2.58$)$ & 2.35 (1.27 to 4.33$)$ & 1.89 (1.16 to 3.07$)$ & 1.77 (1.01 to 3.12$)$ & 1.91 (0.94 to 3.89$)$ & - \\
\hline Ever smoker & 0.99 (0.65 to 1.51$)$ & $0.63(0.37$ to 1.06$)$ & 0.49 (0.30 to 0.80$)$ & 0.61 (0.36 to 1.04$)$ & - & - \\
\hline \multicolumn{7}{|l|}{ Hypertension status and awareness§ } \\
\hline With hypertension and unaware & 1.00 & 1.00 & 1.00 & 1.00 & 1.00 & 1.00 \\
\hline With hypertension and aware & 2.10 (1.28 to 3.43$)$ & 2.51 (1.44 to 4.39$)$ & 2.35 (1.24 to 4.45$)$ & 2.45 (1.21 to 4.94$)$ & 2.17 (0.95 to 4.96$)$ & 2.66 (1.09 to 6.46$)$ \\
\hline With normal blood pressure & $0.71(0.44$ to 1.13$)$ & 0.82 (0.49 to 1.37$)$ & 0.83 (0.48 to 1.45$)$ & $0.96(0.52$ to 1.74$)$ & 0.41 (0.15 to 1.08$)$ & $0.48(0.17$ to 1.31$)$ \\
\hline
\end{tabular}

Above normal refers to $W C>90 \mathrm{~cm}$ in men and $>80 \mathrm{~cm}$ in women.

Bold values indicate statistically significant

*Final model from backward stepwise selection method that included age, sex, traditional social group, educational attainment, occupation, waist circumference, tobacco use, alcohol

consumption, physical activity, health insurance, last time blood pressure (BP) was measured and distance travelled to health services.

†Nine observations missing.

‡Four observations missing.

§This group comprises 132 who are aware of their hypertension, 218 who are unaware of their hypertension and 291 with normal blood pressure.

WC, waist circumference. 
Table 4 Association between taking antihypertensive medication and knowledge of at least two risk factors for hypertension

\begin{tabular}{|c|c|c|c|}
\hline & All & Men & Women \\
\hline Factors & $\begin{array}{l}\text { Multivariable analysis* } \\
\text { OR }(95 \% \mathrm{Cl})\end{array}$ & $\begin{array}{l}\text { Multivariable analysis* } \\
\text { OR }(95 \% \mathrm{Cl})\end{array}$ & $\begin{array}{l}\text { Multivariable analysis* } \\
\text { OR }(95 \% \mathrm{Cl})\end{array}$ \\
\hline Age, year (continuous) & $0.97(0.95$ to 0.99$)$ & 0.97 (0.95 to 0.99$)$ & $0.97(0.93$ to 1.00$)$ \\
\hline Male & 2.64 (1.44 to 4.86$)$ & - & - \\
\hline \multicolumn{4}{|l|}{ Educational attainment ${ }^{\dagger}$} \\
\hline No formal schooling & 1.00 & 1.00 & \\
\hline Some schooling & 1.94 (1.14 to 3.30$)$ & 2.10 (1.10 to 4.02$)$ & - \\
\hline WC above normal $\ddagger$ & 1.86 (1.12 to 3.09$)$ & - & $2.39(1.05$ to 5.43$)$ \\
\hline Physical inactivity & 1.59 (0.99 to 2.54$)$ & 1.74 (0.99 to 3.07 ) & - \\
\hline Ever smoker & 0.62 (0.37 to 1.05$)$ & 0.61 (0.36 to 1.05$)$ & - \\
\hline \multicolumn{4}{|l|}{ Hypertension status and medication§ } \\
\hline With hypertension and not on medication & 1.00 & 1.00 & 1.00 \\
\hline With hypertension and on medication & $3.36(1.78$ to 6.31$)$ & 3.09 (1.34 to 7.11$)$ & $3.62(1.38$ to 9.45$)$ \\
\hline With normal blood pressure & $0.75(0.46$ to 1.21$)$ & $0.85(0.49$ to 1.50$)$ & $0.90(0.12$ to 7.03$)$ \\
\hline
\end{tabular}

Above normal refers to $W C>90 \mathrm{~cm}$ in men and $>80 \mathrm{~cm}$ in women

Bold values indicate statistically significant

*Final model from backward stepwise selection method that included age, sex, traditional social group, educational attainment, occupation, waist circumference, tobacco use, alcohol

consumption, physical activity, health insurance, last time blood pressure (BP) was measured and distance travelled to health services.

†Nine observations missing.

‡Four observations missing.

§This includes 75 participants with hypertension and on medication, 275 participants with hypertension and not on medication and 291 participants with normal blood pressure.

WC, waist circumference.

hypertension, are underway. ${ }^{26} 27$ These studies may provide the evidence required for implementation of such interventions in rural areas.

\section{Limitations and strengths}

There are potential limitations of the present study that should be considered in the interpretation of our findings. It is recommended that the diagnosis of hypertension is based on the average of at least two BP readings taken at two or more visits. ${ }^{28}$ We defined hypertension as an average of two BP readings taken at just a single visit, potentially resulting in either misclassification bias or detection of white-coat hypertension. Nevertheless, our method is in accordance with the recommendations from the WHO STEPS of chronic diseases in population-based surveys. ${ }^{16}$ Second, our study is limited by the observational nature which precludes inference of causality. We also limited our investigation to five known modifiable risk factors for hypertension, excluding other potential factors such as smoking, where data are inconsistent. ${ }^{29-32}$ Our findings are also limited to similar populations and are not generalisable to India as a whole. Lastly, because there is no standardised instrument available to assess knowledge about hypertension in our population, we used existing literature to design our questionnaire. We acknowledge that the questionnaire used in this study has not been validated, but was pretested for acceptability and relevance in a group of residents.

The above limitations notwithstanding, our study is strengthened by a large sample size, standardised methods and the potential for our findings to be generalised to similar populations in India and other LMICs, where similar characteristics are observed. To the best of our knowledge, our findings are the first to clearly demonstrate factors associated with knowledge of risk factors for hypertension in rural India. Our findings have profound implications to inform public health policies aimed at improving knowledge about hypertension in rural populations of India, and consequently, for strategies aimed towards improving health behaviours and reducing the burden of this disease.

\section{CONCLUSIONS}

Our findings highlight poor knowledge of modifiable risk factors and consequences of hypertension in a disadvantaged rural Indian population. Awareness of hypertension and taking antihypertensive medication are associated with improvement of knowledge. Screening programmes to increase awareness of hypertension, and broadly targeted educational programmes aimed at improving knowledge throughout the community, should be a priority.

Acknowledgements We gratefully acknowledge the healthcare workers and study staff who undertook the fieldwork and data collection for this study. DB is grateful for financial support received from the Monash University Postgraduate Publications Award.

Contributors AGT, RGE and VKS contributed to the conception of the study. DB performed statistical analyses and drafted the manuscript. All authors contributed to the design of the study and interpretation of the findings, and contributed to the revision of the manuscript and approved the final version.

Funding The project was funded by project grants from the National Health and Medical Research Council (NHMRC), Australia (1005740 and 1040030). AGT was supported by a Senior Research Fellowship from the NHMRC, Australia (1042600). VKS was supported by an NHMRC Career Development Fellowship (1061457) and a Heart Foundation Future Leader Fellowship (100089). DB was supported by a Monash Faculty of Medicine International Postgraduate Scholarship, a part Monash Graduate Scholarship and a Department of Medicine Top-up award.

Competing interests None declared.

Patient consent for publication Not required.

Ethics approval The study was approved by the Human Ethics Committees of Monash University, the Rishi Valley Education Centre (50/1/Indo-CVD/2-8/NCD II) and the Indian Council of Medical Research (2006/073MC).

Provenance and peer review Not commissioned; externally peer reviewed.

\section{REFERENCES}

1. Forouzanfar MH, Alexander L, Anderson HR, et al. Global, regional, and national comparative risk assessment of 79 behavioural, environmental and occupational, and metabolic risks or clusters of risks in 188 countries, 1990-2013: a systematic analysis for the global burden of Disease Study 2013. Lancet 2015:386:2287-323.

2. Pradeepa R, Mohan V, Hypertension MV. Hypertension \& pre-hypertension in developing countries. Indian J Med Res 2008;128:688-90. 
3. Chow CK, Teo KK, Rangarajan S, et al. Prevalence, awareness, treatment, and control of hypertension in rural and urban communities in high-, middle-, and low-income countries. JAMA 2013;310:959-68.

4. Garrison RJ, Kannel WB, Stokes J, et al. Incidence and precursors of hypertension in young adults: the Framingham offspring study. Prev Med 1987;16:235-51.

5. Knight EL, Bohn RL, Wang PS, et al. Predictors of uncontrolled hypertension in ambulatory patients. Hypertension 2001;38:809-14.

6. Zhang $X$, Zhu M, Dib HH, et al. Knowledge, awareness, behavior (KAB) and control of hypertension among urban elderly in Western China. Int J Cardiol 2009;137:9-15.

7. Ambaw AD, Alemie GA, W/Yohannes SM, et al. Adherence to antihypertensive treatment and associated factors among patients on follow up at University of Gondar Hospital, Northwest Ethiopia. BMC Public Health 2012;12.

8. Kim E-Y, Han H-R, Jeong $\mathrm{S}$, et al. Does knowledge matter?: intentional medication nonadherence among middle-aged Korean Americans with high blood pressure. J Cardiovasc Nurs 2007;22:397-404.

9. Babaee Beigi MA, Zibaeenezhad MJ, Aghasadeghi K, et al. The effect of educational programs on hypertension management. Int Cardiovasc Res J 2014;8:94-8.

10. Huang $\mathrm{S}, \mathrm{Hu} \mathrm{X}, \mathrm{Chen} \mathrm{H}$, et al. The positive effect of an intervention program on the hypertension knowledge and lifestyles of rural residents over the age of 35 years in an area of China. Hypertens Res 2011;34:503-8.

11. Slark J, Khan MS, Bentley P, et al. Knowledge of blood pressure in a U.K. general public population. J Hum Hypertens 2014;28:500-3.

12. Sanne $S$, Muntner $P$, Kawasaki L, et al. Hypertension knowledge among patients from an urban clinic. Ethn Dis 2008;18:42-7.

13. Volpe M, Dedhiya SD, Physicians DSD. Physicians, patients, and public knowledge and perception regarding hypertension and stroke: a review of survey studies. Curr Med Res Opin 2006:22:1319-30.

14. Kearney PM, Whelton M, Reynolds K, et al. Global burden of hypertension: analysis of worldwide data. Lancet 2005;365:217-23.

15. Aubert L, Bovet $P$, Gervasoni JP, et al. Knowledge, attitudes, and practices on hypertension in a country in epidemiological transition. Hypertension 1998:31:1136-45.

16. World Health Organization. Stepwise approach to chronic disease surveillance (steps): training and practical guides overview. Geneva, 2008.

17. Burt VL, Whelton P, Roccella EJ, et al. Prevalence of hypertension in the US adult population. Results from the third National Health and Nutrition Examination Survey, 1988-1991. Hypertension 1995;25:305-13.

18. Misra A, Chowbey P, Makkar BM, et al. Consensus statement for diagnosis of obesity, abdominal obesity and the metabolic syndrome for Asian Indians and recommendations for physical activity, medical and surgical management. J Assoc Physicians India 2009;57:163-70.

19. Nayar KR, Social exclusion caste. Social exclusion, caste \& health: a review based on the social determinants framework. Indian J Med Res 2007;126:355-63.

20. Ludbrook J. On making multiple comparisons in clinical and experimental pharmacology and physiology. Clin Exp Pharmacol Physiol 1991;18:379-92.

21. Aung MN, Lorga T, Srikrajang J, et al. Assessing awareness and knowledge of hypertension in an at-risk population in the Karen ethnic rural community, Thasongyang, Thailand. Int J Gen Med 2012;5:553-61.

22. Mittal BV, Singh AK. Hypertension in the developing world: challenges and opportunities. Am J Kidney Dis 2010;55:590-8.

23. Zaman MJ, Patel A, Jan S, et al. Socio-economic distribution of cardiovascular risk factors and knowledge in rural India. Int J Epidemiol 2012;41:1302-14.

24. Piette JD, List J, Rana GK, et al. Mobile health devices as tools for worldwide cardiovascular risk reduction and disease management. Circulation 2015; 132:2012-27.

25. DeSouza SI, Rashmi MR, Vasanthi AP, et al. Mobile phones: the next step towards healthcare delivery in rural India? PLoS One 2014;9:e104895.

26. Raghu A, Praveen D, Peiris D, et al. Engineering a mobile health tool for resource-poor settings to assess and manage cardiovascular disease risk: SMARThealth study. BMC Med Inform Decis Mak 2015;15.

27. Arulogun OS, Hurst S, Owolabi MO, et al. Experience of using an interdisciplinary task force to develop a culturally sensitive multipronged tool to improve stroke outcomes in Nigeria. eNeurologicalSci 2016;4:10-14.

28. Mancia G, Fagard R, Narkiewicz K, et al. 2013 ESH/ESC guidelines for the management of arterial hypertension: the task Force for the management of arterial hypertension of the European Society of hypertension (ESH) and of the European Society of cardiology (ESC). J Hypertens 2013;31:1281-357.

29. Gupta R, Agarwal VS, Gupta VP. Correlation of smoking, blood pressure levels and hypertension prevalence in urban and rural subjects. J Assoc Physicians India 1997;45:919-22.

30. Kaur P, Rao SR, Radhakrishnan E, et al. Prevalence, awareness, treatment, control and risk factors for hypertension in a rural population in South India. Int J Public Health 2012; 57:87-94.

31. Midha T, Idris MZ, Saran RK, et al. Prevalence and determinants of hypertension in the urban and rural population of a North Indian district. East Afr J Public Health 2009:6:268-73.

32. Sathish T, Kannan S, Sarma PS, et al. Incidence of hypertension and its risk factors in rural Kerala, India: a community-based cohort study. Public Health 2012;126:25-32. 